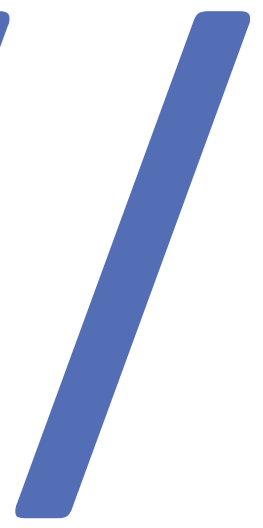

\title{
Poéticas e políticas do rosto na era das imagens inteligentes
}

\section{Poetics and politics of the} face in the age of smart images

\section{Icaro Ferraz Vidal Junior ${ }^{1}$}

\footnotetext{
${ }^{1}$ Mestre em Comunicação e Cultura pela Universidade Federal do Rio de Janeiro e em "Crossways in European Humanities" pelas Universidade Nova de Lisboa, Universidade de Santiago de Compostela e University of Sheffield, doutor em "Cultural Studies in Literary Interzones" pelas Université de Perpignan Via Domitia e Università degli studi di Bergamo e em Comunicação e Cultura pela Universidade Federal do Rio de Janeiro. Realizou estágio pós-doutoral no Programa de Pós-Graduação em Comunicação e Linguagens da Universidade Tuiuti do Paraná (2017-2018). Atualmente é bolsista de pós-doutorado PNPD-Capes no Programa de Estudos Pós-Graduados em Comunicação e Semiótica da Pontifícia Universidade Católica de São Paulo. É pesquisador do Centro Interdisciplinar de Semiótica da Cultura e da Mídia (CISC/PUC-SP), do JUVENÁLIA - Culturas juvenis: comunicação, imagem, política e consumo (ESPM-SP) e do MediaLab UFRJ. E-mail: vidal.icaro@gmail.com
} 
Resumo: O presente artigo explora algumas inflexões contemporâneas no estatuto do rosto. $\mathrm{Na}$ arte contemporânea, em sistemas de vídeo-vigilância, no marketing, na pornografia etc. as tecnologias de detecção e reconhecimento facial parecem espraiar-se sobre uma vasta gama de domínios. Sem a pretensão de esgotar este campo, propomos traçar algumas linhas de força que nos ajudem a compreender o que está em jogo nessa reconfiguração estética e política dos rostos. A partir de noções que buscamos no pensamento de autores como Michel Foucault, Giorgio Agamben, Gilles Deleuze e Félix Guattari, cartografamos algumas tensões entre ação e representação, cristalizadas no estatuto contemporâneo do rosto.

Palavras-chave: rosto; algoritmo; reconhecimento facial; arte contemporânea; pornografia.

Abstract: This article explores some contemporary inflections about the status of the face. In contemporary art, in surveillance systems, in marketing practices, in pornography etc.; facial recognition and detection technologies seem to be spreading over a wide range of domains. Not intending to exhaust the theme, we will try to draw some lines of force that aid us in understanding what is at stake in this aesthetic and political reconfiguration of the faces. From some notions we have sought in the works of authors like Michel Foucault, Giorgio Agamben, Gilles Deleuze and Félix Guattari, we have mapped some tensions between action and representation, crystallized in the contemporary status of the face.

Keywords: face; algorithm; facial recognition; contemporary art; pornography. 
Em Der Ausdruck der Hände (A expressão das mãos, 1997), Harun Farocki reivindica uma diferença entre close-up das mãos e close-up do rosto, inscrevendo uma tensão entre tais imagens. Frequentemente, diz a voz em off, a imagem das mãos expressa algo que o rosto tenta esconder. Uma outra diferença sublinhada por Farocki é que a imagem de um rosto pode substituir a inteireza de uma pessoa, ao passo que isto não se dá, ao menos no cinema clássico, com nenhuma outra parte do corpo (ERNST; FAROCKI, 2004). Às mãos, normalmente, vincula-se uma ação; ao rosto, uma identidade.

Nas páginas que seguem, nos ocuparemos do campo de pesquisa dedicado ao reconhecimento e à detecção facial por câmeras inteligentes, buscando identificar algumas linhas de força nesta reconfiguração estética e política dos rostos. As tensões entre ação e representação e entre gesto e identidade, que perpassam a leitura de Farocki das imagens do rosto, servirão aqui como o fio com o qual costuraremos um corpus intencionalmente heterogêneo. Tal heterogeneidade não tem outro propósito senão o de indicar a escala das transformações em curso e a complexidade das redes que subjazem a (des)feitura de nossos rostos.

\section{O rosto, um código barras}

Em um breve artigo, Aram Sinnreich, professor da American University, em Washington, descreve o cenário no qual as tecnologias de detecção e reconhecimento facial ingressaram no repertório de ferramentas do marketing, inaugurando novos dilemas éticos e demandando a criação de novas estratégias de resistência por parte de usuários/consumidores. Este cenário é apresentado por Sinnreich (2017, s/p)² nos seguintes termos:

Como o antigo orador romano Cícero uma vez colocou, "O rosto é o index da alma”. Em 2017, nossos rostos são mais index.html do que index - graças a novos softwares de leiturafacial que podem fazer tudo, de revelar suas emoções secretas a descobrir sua localização, e mesmo predizer o que você fará a seguir.

Em 2016, a Apple adquiriu uma startup de tecnologia chamada Emotient, desenvolvedora de um software de reconhecimento facial. De acordo com nota publicada pela Reuters, os termos financeiros da compra, bem como os planos da Apple não foram declarados. A nota da agência de notícias, entretanto, explicita

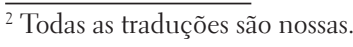


potenciais usos para o software desenvolvido pela Emotient: "O software da Emotient lê as expressões de indivíduos e multidões para ganhar um discernimento que pode ser usado por publicitários para avaliar as reações de espectadores ou por um médico para melhor compreender signos de dor em um paciente” (APPLE..., 2016, s/p).

Sinnreich comenta a recente aquisição de Emotient pela Apple, enfatizando a presença de câmeras em praticamente todos os dispositivos da marca. Esta presença abriria a possibilidade, em teoria, de empresas pagarem à Apple pelo acesso às reações de usuários a certos anúncios publicitários e, dessa forma, sofisticarem ainda mais o processo de customização algorítmica, como o que já está em operação no Google AdSense ou no sistema de sugestões da Amazon, baseados, até agora, em palavraschave e nos históricos de busca, navegação e compras dos usuários.

Apesar do tom apocalíptico de seu texto, remediado pela sugestão de novas formas de resistência ao fim do artigo, veremos, a partir de uma série de práticas que irão compor esta nossa cartografia, que a analogia feita por Sinnreich entre nossos rostos e os QR codes não é apenas uma metáfora.

\begin{abstract}
A tecnologia $[\ldots]$ pode agora ler rostos melhor do que humanos podem. Isto significa que nossos rostos têm efetivamente se tornado indeléveis QR codes ou "códigos de barra" - matrizes digitais que identificam um tipo de produto e preço - que carregamos sobre nossas pessoas todo o tempo, dando a qualquer um com uma câmera e acesso à internet a habilidade para minerar informações profundas sobre nossas vidas pessoais, e para usar ambos, nossos rostos e as informações associadas a eles, em qualquer forma concebível, sem nosso conhecimento ou consentimento. (SINNREICH, 2017, s/p)
\end{abstract}

A esta objeção, associada à questão da privacidade e ao direito sobre a própria imagem, desenvolvedores e grandes corporações respondem assegurando - a partir da diferença entre detecção e reconhecimento facial - que grande parte das aplicações de tais tecnologias consiste em detecção de rostos, ou seja, reconhece-se um rosto sem associá-lo a uma pessoa em particular. É o caso, por exemplo, do Google Photos ou do aplicativo de fotos da Apple, que reconhecem rostos nas fotografias armazenadas e as agrupam por similaridade, oferecendo ao usuário a opção de vincular um conjunto de faces a um nome, sem, no entanto, realizar tal procedimento automaticamente, como chegou a ser proposto pelo Facebook há alguns anos.

A partir de um cenário hipotético de utilização de tecnologias de reconhecimento facial pelo marketing, Sinnreich dá uma pista interessante acerca de um possível futuro para nossos rostos. Tal cenário prevê um anúncio publicitário para 
telefone celular que seria sensível à expressão facial, de modo a verificar nossa tendência a fazer determinada compra. Em função de tal análise, a mensagem publicitária texto, diagramação etc. - poderia ajustar-se até uma expressão mais aberta à proposta de compra por parte do usuário ser reconhecida pelo sistema. O exemplo fornecido pelo autor é o de uma lanchonete. Ele imagina que ao passarmos perto do estabelecimento, recebemos uma mensagem publicitária em nosso telefone oferendo 50 centavos de desconto no preço do sanduíche. Se o dispositivo identifica desinteresse em nosso rosto, um novo anúncio é gerado oferecendo 1 dólar de desconto, de modo a verificar se o desinteresse permanece ou se se trata de um potencial cliente. Segundo ele, neste cenário, provavelmente aprenderíamos rapidamente a simular uma certa expressão de desinteresse de modo a obter melhores descontos.

Duas questões saltam aos olhos na predição de Sinnreich. A primeira tem a ver com a aparente ausência de qualquer exterioridade à lógica do consumo sobre a qual, diante da inteligência dos novos dispositivos, parece que perdemos qualquer capacidade de hesitar. Jogar é o verbo que o autor utiliza para falar destas expressões faciais que seriam aprendidas de modo a viabilizar melhores negócios para os usuários. O problema desta lógica é que não temos nenhuma chance de "ganhar este jogo", já que este processo desemboca, com maior ou menor prejuízo econômico para o usuário, em um ato de consumo que pode ser compreendido como uma reação quase instantânea a um estímulo exterior, não sendo organizado em torno da ideia de satisfação de uma necessidade, nem da realização de um desejo. Nem Darwin, nem Freud poderiam nos ajudar a compreender esta compra. Talvez o repertório conceitual que melhor explique a temporalidade deste tipo emergente de consumo encontre-se em Pavlov.

A segunda questão que derivamos deste exemplo tem a ver com o fato de que tendemos a pensar na lógica de detecção e reconhecimento facial atribuindo ao ator humano um caráter passivo. Dessa forma, corroboramos, em alguma medida, a noção de que o rosto seria a manifestação visível e involuntária da alma quando, de fato, nem no regime fotográfico de produção de imagens esta passividade deu-se de modo não problemático. Algumas imagens apresentadas por Tom Gunning (1995) em seu artigo sobre os usos policiais da fotografia mostram que, conscientes do efeito de captura identitária pela máquina fotográfica e lançando mão dos largos períodos de exposição que eram requeridos pelas câmeras de finais do século XIX e começo do século XX para a produção de uma imagem, toda uma série de caretas e, no limite de um rosto já capturado, desfigurações, tiveram lugar. Mas é importante destacar que a pervasividade dos novos dispositivos de captura, detecção e reconhecimento facial instaura um desafio sem precedentes a nossos rostos. 
Tal desafio pode ser inscrito no contexto que Gilles Deleuze (2006) diagnosticou e descreveu a partir do conceito de "sociedade controle". Se a captura de rostos tal como descrita por Gunning esteve modernamente vinculada ao domínio institucional disciplinar, marcado pela passagem por sucessivos confinamentos, hoje a ubiquidade dos dispositivos de controle a céu aberto dificultam o estabelecimento de fronteiras entre contextos controlados e contextos não-controlados. O rosto, frequentemente desnudo ${ }^{3}$, inscreve-se nesse cenário como assinatura involuntária, de modo que o momento de desfazer-se dele já não parece ser prescrito por um mug shot, que marcaria o ingresso de um rosto no arquivo. Os arquivos de nossa era vão sendo alimentados com nossos rostos na medida em que vivemos on-line e off-line ${ }^{4}$.

\section{Políticas do rosto}

Em Face politics, Jenny Edkins (2015) sistematiza algumas problemáticas em torno das relações entre rosto e política. Entre elas, interessa-nos retomar o diagnóstico de uma contradição entre um processo que parece implicar o desaparecimento dos rostos, na medida em que as tecnologias de produção de imagens digitais e um emergente pós-humanismo promovem deslocamentos epistemológicos inéditos cuja tendência é radicalizar o processo de tradução do mundo em unidades decodificáveis de informação, armazenáveis e transmissíveis; e a permanência do rosto como emblema de uma pessoalidade política.

Se o investimento de câmeras inteligentes sobre os rostos catalisa a referida mutação epistemológica, a centralidade do rosto na política atravessa outros regimes tecnopolíticos ao longo da história e não constitui uma novidade incrementada pelas câmeras inteligentes. Uma controvérsia recente, de eloquência no debate acerca da centralidade do rosto na política, foi aquela em torno do anonimato obtido através do uso de máscaras por parte de manifestantes e policiais que participaram das hoje chamadas jornadas de junho, em 201355. O aumento no número de manifestações no Brasil neste período, a partir do ato do dia 13 de junho em São Paulo, marcado

\footnotetext{
${ }^{3}$ A controvérsia a respeito da legitimidade do encobrimento dos rostos em manifestações públicas, da qual nos ocuparemos a seguir, assim como a criminalização, na França, do uso de burka por mulheres muçulmanas, atestam o desnudamento dos rostos como condição da vida pública, nos moldes em que esta vem sendo postulada pelos Estados modernos.

${ }^{4}$ Sobre a recente implementação de dispositivos de reconhecimento e mensuração de expressões faciais com fins comerciais pela ViaQ̧uatro, concessionária da operação da linha 4 do Metrô de São Paulo, cf. Montagner (2018).

${ }^{5}$ Uma cartografia desta controvérsia pode ser consultada em Anonimato \#ProtestosBR, disponível em: $<$ http://bit.ly/2LM2lxr>. Acesso em: 15 dez. 2018.
} 
por violentos confrontos entre policiais e manifestantes, introduziu uma agenda, nos meios de comunicação, que dizia respeito às condutas - aceitáveis ou não - por parte de policiais e manifestantes no contexto de atos públicos. A violência da Polícia Militar e a emergência de um novo ator político - os black blocs -, cujas ações seriam marcadas por táticas de guerrilha e pelo uso de máscaras, polarizaram a disputa em torno do direito à proteção da própria identidade através do encobrimento do rosto.

Amplamente divulgada nas redes sociais até ser censurada, uma imagem da ocupação da Câmara dos Vereadores de Porto Alegre tornou-se emblemática desta controvérsia, resumindo uma série de tensões interiores ao sistema político representativo, que reverberam na política dos rostos. A imagem apresenta um grupo de manifestantes nus, com seus rostos cobertos, diante da galeria de retratos dos vereadores em exercício naquele momento. A opinião pública, muito mobilizada na época pela ideia de vandalismo que foi agenciada discursivamente como definindo qualquer resistência mais ativa ao poder instituído, opôs-se ao uso de máscara por manifestantes, associando o encobrimento do rosto à ação criminosa. Bem menos discutido pela grande mídia foi o fato de em vários atos a própria polícia atuar sem as identificações no fardamento, previstas em lei, e com os rostos igualmente encobertos, seja por máscaras de gás, capacetes ou gorros.

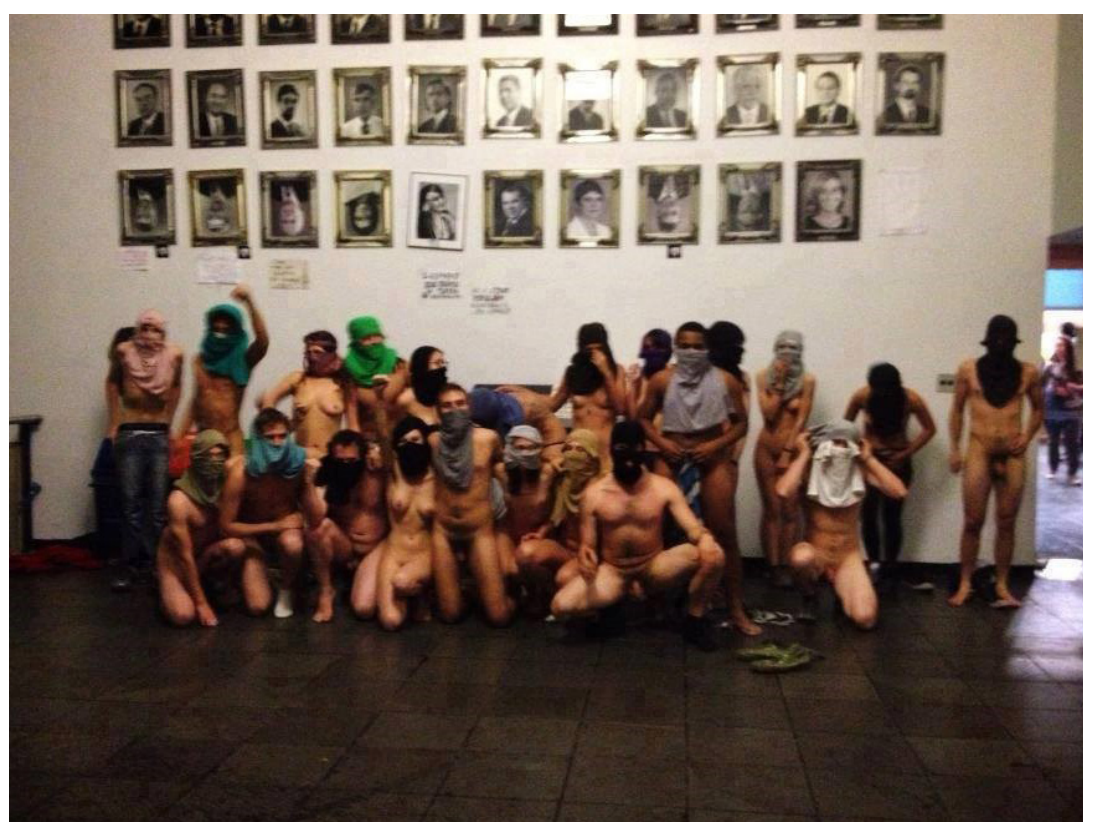

Figura 1: Ocupação da Câmara de Vereadores de Porto Alegre, postada no Facebook no dia 18 de julho de 2013. 
Iremos reivindicar que o que a imagem acima apresenta excede o contexto histórico das jornadas de junho. Nela parecem convergir e se tensionar dois modos de organização, distribuição e entendimento da política, que são distintos e de difícil conciliação. Por um lado, a presença dos vereadores através de seus retratos vincula-se a uma ideia, fundamentalmente moderna e ocidental de sujeito.

Historiadores da arte vinculam mais frequentemente os retratos a um período particular da história europeia: um período quando a pessoa estava começando a ser concebida como um indivíduo, um ser separado de outros seres. No tempo em que o retrato estava tornando-se proeminente como uma forma de arte, na renascença italiana, a pessoa estava começando a ser vista como, antes de tudo, separada. A questão política chave no pensamento ocidental tornou-se - e tem permanecido amplamente - a questão de como estes indivíduos separados deveriam viver com outros. (EDKINS, 2015, p. xvi)

A própria Câmara de Vereadores, operando segundo uma lógica de representação, é uma das soluções historicamente encontradas no contexto dos países democráticos para o problema instaurado a partir da redução da pessoa a um indivíduo, da qual o retrato foi um dos mais evidentes efeitos-instrumento (FOUCAULT, 1988). A política, em um mundo no qual as pessoas existem como unidades identitárias e onde, por uma série de razões (inclusive demográficas), a participação direta na esfera pública é dificilmente imaginável, a representação parece ter sido a única solução democrática colocada em prática. Os limites deste modelo foram atestados por uma palavra de ordem que marcou este período de efervescência política no Brasil: os variados sujeitos que compuseram a frase "não me representa" pareciam apontar mais para os limites da própria representação do que para a descrença em um ou outro ator político em particular.

A este modo de organização, distribuição e entendimento da política, emblematizado pelos retratos dos vereadores, opõem-se, na parte inferior da imagem, os corpos nus e mascarados dos ativistas que ocuparam a instituição, sinalizando fraturas e incongruências da representação política supostamente democrática. Sem adentrarmos na crise do sistema político brasileiro, é importante destacar que, mais do que uma nostalgia, tais processos parecem indicar a necessidade de uma urgente reinvenção da política. Algumas orientações possivelmente úteis a esse processo podem ser intuídas a partir da imagem acima.

Os retratos dos vereadores instauram uma relação perceptiva necessariamente vertical, que é desafiada, no ato em questão, pela inversão de alguns retratos, 
colocando a própria política de cabeça para baixo. A isso soma-se o fato de que as molduras continuam a operar, histórica e funcionalmente, uma separação do retrato - e do retratado - em relação ao seu entorno. Em uma outra direção, o coletivo que margeia a parede de retratos parece instaurar outras dinâmicas, e o ocultamento de seus rostos pode ser lido, a partir de Deleuze e Guattari (1980), como um desfazimento do rosto. E tal desfazimento, iremos reivindicar, pode vir a desempenhar um papel crucial na proposição desta nova configuração da política.

Aos modernos indivíduos, a multidão nua opõe a horizontalidade e continuidade dos corpos. As molduras enquadrando os rostos, que presentificam os retratados no espaço do parlamento (em um regime de presença-ausência caro à fotografia) podem ser pensadas como análogas às roupas das quais os manifestantes despiram-se. No plano da representação, estética e política, a moldura destaca, sublinha e separa nos mesmos termos em que, no plano da presença social e histórica, a roupa emoldura os corpos, sublimando o que eles têm de comum e operando uma separação e hierarquização entre eles. A radicalidade deste argumento não precisa ser levada aqui ao pé-da-letra, afinal, sabemos que a multidão nem sempre prescindiu da nudez para se impor contra a lógica da representação. Entretanto, nesta fotografia, não apenas os corpos estão despidos, mas os rostos estão cobertos.

O encobrimento destes rostos em particular - mas também o encobrimento de rostos em geral - não está imune às mais variadas controvérsias. Genericamente falando, encobrir um rosto tem sempre por efeito a laminação de uma singularidade que, em nossas sociedades modernas e ocidentais, apenas pôde assumir a forma do individualismo. Escravos, judeus vítimas do holocausto, palestinos e refugiados sírios não possuem um rosto. Soldados e ditadores são um rosto. A despossessão de um rosto por aqueles a quem a história não poupou não é fruto de um encobrimento voluntário, mas de um roubo. Neste sentido, a imagem gaúcha parece ultrapassar uma circunscrição histórica entre opressores e oprimidos reiterando a possibilidade de um regime afirmativo de desfazimento do rosto. Tal regime desindividualiza a resistência, ao mesmo tempo que destaca a impossibilidade de uma política centrada nos indivíduos. Ora, se a política orienta-se em função do futuro da comunidade, separar-se deste plano para exercer uma política a partir de seu exterior implicará um conflito de interesses e, no limite, a gênese de regimes autoritários.

O conceito de biopoder, tal como encontramos em Michel Foucault e reaparece na filosofia de Giorgio Agamben, poderia elucidar o presente argumento. Entretanto, é preciso cautela para que tal enquadramento não esvazie a potência desta imagem, ao reduzi-la a noções que já nos são demasiadamente familiares. 
Os investimentos do biopoder sobre a vida nua, vida destituída de qualquer valor para além de sua persistência biológica na sobrevivência (AGAMBEN, 2002) podem ter desencadeado o ato de resistência em questão, mas isso se deu apenas na medida em que os corpos na fotografia em questão insurgiram enquanto corpos sem rostos, paradoxalmente excedendo qualquer possibilidade de captura. Esses corpos afirmativamente nus e esses rostos deliberadamente encobertos parecem não caber na relação biopoder - vida nua. Eles talvez enfatizem o segundo valor que Judith Revel (2006, p. 53) vinculou ao conceito de biopolítica:

uma biopolítica entendida como expressão da potência de vida face aos poderes, isto é, como uma política da resistência, da diferença; uma biopolítica, portanto, como produção de subjetividade que seja, simultaneamente, crítica daquilo que é e invenção daquilo que será, busca de uma ruptura com o presente e problematização de um devir-outro da atualidade.

Tal observação sustenta-se na medida em que o que parece estar em jogo é uma ressignificação do corpo despido e do rosto desfeito, já não mais a partir de uma ideia de vulnerabilidade e desqualificação. O apagamento da individualidade no contexto a que nos referimos não implica necessariamente uma laminação das diferenças. O conjunto dos corpos na imagem em questão preserva uma heterogeneidade, ao mesmo tempo que viabiliza a produção de um comum a partir do qual a política parecia tornar-se, novamente, possível.

\section{Cobrir o rosto, trocar o sapato}

O trabalho do artista e cineasta brasileiro Gabriel Mascaro Não é sobre sapatos, apresentado na $31^{\text {a }}$ Bienal de Arte de São Paulo, em 2014, também parte do contexto das manifestações de 2013. Em meio à cobertura claramente tendenciosa das manifestações pela grande mídia, uma iniciativa midialivrista, a Mídia Ninja, ganhou enorme visibilidade na época ao registrar com aparelhos celulares e transmitir em live streaming as manifestações, produzindo um caleidoscópio de imagens em primeira pessoa que testemunhavam a desproporcional violência empregada pela Polícia Militar na repressão e dispersão dos atos públicos. Mascaro percorre o caminho inverso, trabalhando sobre imagens que teriam supostamente sido produzidas pela polícia.

A instalação de Mascaro na Bienal contou com a fotografia de um documento aparentemente oficial, intitulado "Saiba como reconhecer lideranças e alimentar o sistema de inteligência da polícia a partir da tática de infiltração" e com um vídeo que teria sido produzido pelos policiais. No vídeo, vemos registros produzidos por uma 
câmera trêmula e errante, parecidos com algumas imagens partilhadas pela Mídia Ninja e, portanto, provavelmente produzidos por um telefone celular. Esta câmera percorre um espaço público no qual uma manifestação está em vias de ocorrer. A câmera detém-se em alguns rostos e nos sapatos de alguns manifestantes. No referido documento que faz parte da instalação, constam dez orientações para a infiltração de policiais nos movimentos de resistência. Entre tais orientações, a última é de particular interesse para nosso argumento:
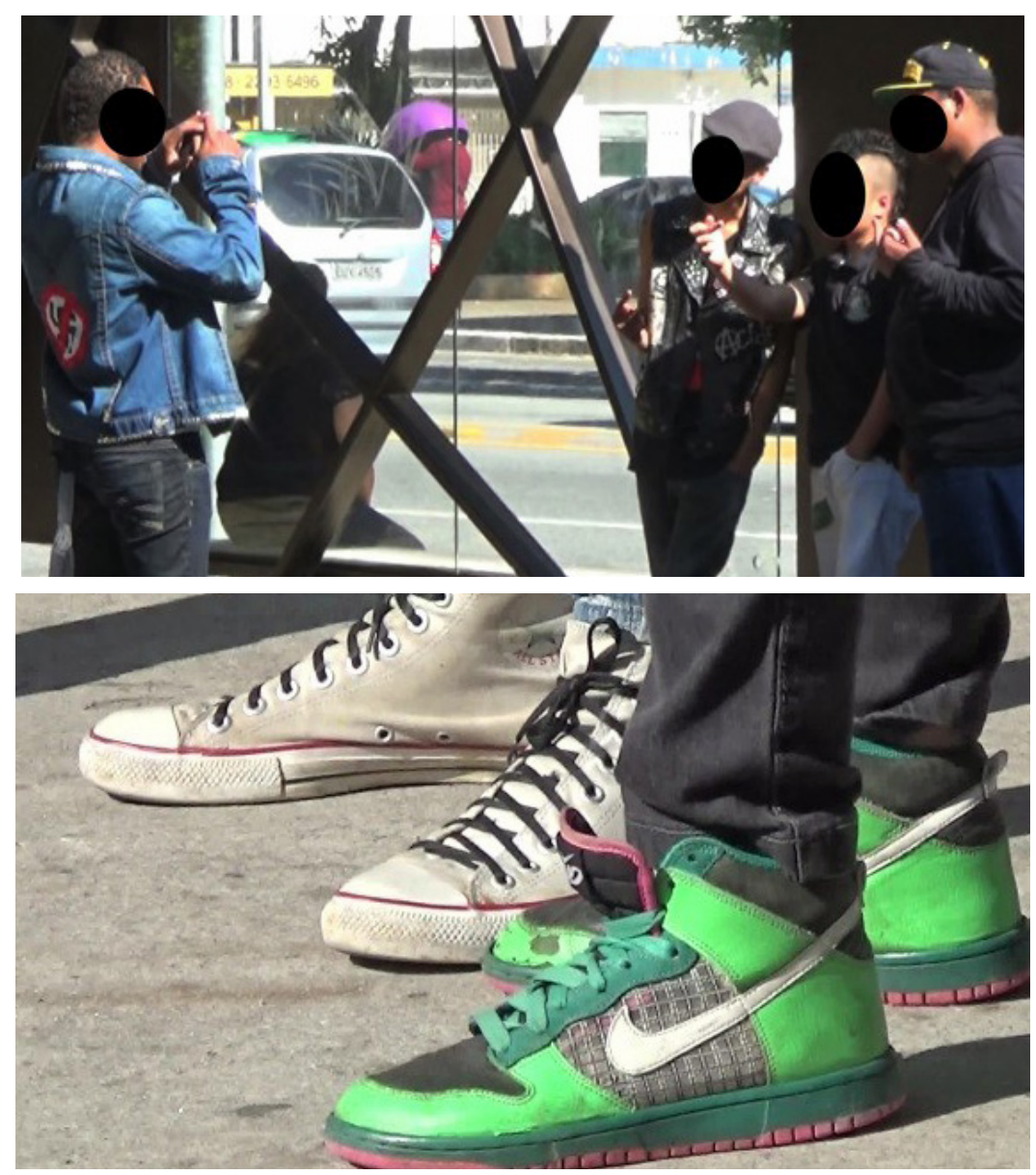

Figuras 2 e 3: Frames de “Não é sobre sapatos”, de Gabriel Mascaro, 2014.

- Em caso de porte de câmera de vídeo na atividade de registro, chegar na manifestação antes do horário previsto. Iniciar o registro mapeando o rosto dos manifestantes em conversas informais e fundamentalmente registrar os sapatos. Uma vez a 
manifestação evolua para atos ilícitos de vandalismo, e alguns manifestantes cobrirem a face ou trocarem de camisa [sic], dificilmente eles trocarão os sapatos. (MASCARO, 2014)

O argumento do trabalho de Mascaro vai de encontro ao exemplo que Edkins oferece para corroborar a tese de Kelly Gates (2011) acerca da insuficiência das tecnologias de reconhecimento facial no contexto de identificação de suspeitos por parte do poder policial. Trata-se do depoimento de Andy Trotter, Chefe de Polícia do Transporte de Londres em 2011, no qual ele confirmava o uso de tecnologias de reconhecimento facial nas investigações ligadas aos Riots, mas enfatizava que tais tecnologias

"fazem apenas uma fração dos esforços da força policial... dicas tinham vindo principalmente de fontes tradicionais, tais como imagens still capturadas de câmeras em circuito fechado, fotografias recolhidas por policiais, filmes feitos por helicópteros da polícia ou imagens vazadas por membros do público”. E, como Trotter apontou, as pessoas podem ser conhecidas por roupas, caminhada, ou tatuagens assim como pelo seu rosto. [...] Um porta-voz de Scotland Yard confirmou que "na maioria dos casos disseminar fotografias para o público geral ainda é a maneira mais barata e efetiva de encontrar suspeitos" do que tecnologia de reconhecimento facial. A tecnologia é útil apenas para identificar alguém cujo rosto já está "nos registros", e onde a polícia tem um retrato de boa qualidade para fins de comparação. (EDKINS, 2015, p. 99-100)

O desdobramento do cenário descrito acima, notadamente o fato de as tecnologias de reconhecimento facial serem tão mais eficazes quanto mais completo é o arquivo de retratos de que se dispõe, aponta, em contexto de acelerada expansão de redes sociais nas quais nossas ações são mediadas por avatares antropomórficos (JOHNSON, 1997), na direção de uma efetiva otimização de tais tecnologias. As bases de dados das redes sociais - muitas delas publicamente acessíveis - fornecem solo fértil para o avanço da capacidade maquínica de encontrar nossos rostos na multidão. Entretanto, a estratégia descrita na obra de Mascaro, seja ela ficcional ou não, alinha-se ao depoimento de Trotter, sinalizando a ambivalência do rosto nos processos policiais de identificação: ele é um elemento central em tais processos, mas parece ser, por vezes, fugidio.

\section{$\mathrm{O}$ rosto estatístico}

As tecnologias de reconhecimento facial herdam uma história que é anterior a sua aparição na forma que encontramos atualmente. "Reconhecimento facial 
mede o tamanho e a separação de características faciais para identificar indivíduos; eugenia faz o mesmo, desta vez para identificar agrupamentos de indivíduos de acordo com sua origem étnica ou racial" (EDKINS, 2015, p. 102-103). Não iremos reivindicar aqui a existência de uma simples linha de continuidade, marcada pelo aperfeiçoamento tecnológico, entre a eugenia e as técnicas de reconhecimento facial.

Enquanto a fisionomia e a frenologia foram saberes (considerados científicos em certo tempo) que partiam do pressuposto de características faciais e formato do crânio indicarem traços da personalidade e do caráter de um determinado indivíduo, o que acabou por criar um ranking eurocêntrico que contava em sua ponta superior com o tipo ariano e na ponta inferior com negros e judeus; as tecnologias de reconhecimento facial parecem promover um deslocamento da ênfase nos marcadores étnicos e raciais para uma ênfase na conduta de seres dividuais, como teria formulado Deleuze (2006).

Os saberes forjados a partir da popularização da fotografia em finais do século XIX, desembocando na conhecida e temida eugenia, estiveram comprometidos com a sistematização de certos tipos, ao passo que as tecnologias digitais de reconhecimento facial operam a partir de eventuais traços comuns entre o rosto a ser identificado e uma vasta gama de rostos armazenados em bancos de dados cada vez maiores. Apesar das várias diferenças entre os saberes que fundamentaram as políticas eugênicas e as atuais tecnologias computadorizadas de reconhecimento facial, há um aspecto que atravessa os dois contextos. Trata-se de uma aparente tensão entre um processo de emergência e popularização de determinado meio técnico e o incremento de vigilância e controle por parte do Estado. Allan Sekula (1989, p. 62) aborda esta permanência nos seguintes termos:

Bertillon e Galton ainda estão conosco. "Bertillon" sobrevive nas operações da segurança pública nacional, na condição da vigilância intensiva e extensiva que caracteriza a vida cotidiana e a esfera geopolítica. "Galton" vive na renovada autoridade do determinismo biológico [e] nas implicações neo-eugênicas de algumas das novas biotecnologias.

Apesar dos argumentos de Sekula e Edkins - que enfatizam uma linha de continuidade e um aperfeiçoamento entre os saberes eugênicos e as tecnologias de reconhecimento facial - não serem inconsistentes, parece-nos que tais argumentos negligenciam transformações importantes tanto do ponto de vista da lógica e da materialidade implicadas nas tecnologias utilizadas para reconhecimento facial 
quanto do ponto de vista das intencionalidades não-subjetivas que atravessam e constituem nossa formação histórica.

A chamada crise das instituições disciplinares, que marca a segunda metade do século XX, e o desenvolvimento de novas tecnologias de comunicação e informação nas últimas duas décadas do século passado viabilizaram a instauração de novas dinâmicas de articulação entre os poderes instituídos e os corpos. Evidentemente, alguns aspectos dessas novas formas de investimento do poder sobre os sujeitos já estavam, em alguma medida, formuladas no interior do pensamento foucaultiano, notadamente na produtividade e na positividade do biopoder, já no primeiro volume de sua História da sexualidade (1988). Gilles Deleuze desdobra, a partir de numerosos exemplos, o declínio das sociedades disciplinares, nas quais as trajetórias de vida dos sujeitos eram marcadas por uma sucessão de confinamentos, aos quais a prisão servia de modelo, e aponta para a emergência de um regime fluido de circulação dos corpos, já não confinados ou sujeitos aos limites inscritos pelos muros das instituições disciplinares.

Pensemos, por exemplo, na diferença entre os tipos formulados por Galton e as tecnologias de reconhecimento facial baseadas em vastos bancos de dados, nas quais o uso da estatística já não serve à formulação de um tipo mas à comparação automática de uma imagem-alvo com cada uma das demais imagens que compõem o referido arquivo. O ponto de partida, neste último caso, é simetricamente oposto àquele proposto por Galton e nos parece bastante eloquente acerca do declínio da estruturação disciplinar da sociedade, bem como da crise de representação que a fotografia da ocupação da Câmara de Vereadores de Porto Alegre dá a ver. A criação de um tipo negro ou de um tipo judeu corresponderia, no interior do argumento deleuziano, aos moldes. Nas sociedades disciplinares os sujeitos são submetidos a certos moldes. As instituições disciplinares estavam organizadas em torno de um conjunto de características claramente definidas e muitas vezes quantificáveis, a partir das quais emergiam figuras como o bom e o mau aluno, o bom e o mau operário etc. Os tipos de Galton operam mais ou menos nesta lógica: eles fornecem moldes étnicos e raciais aos quais os vários indivíduos serão aproximados e enquadrados e, em função deste enquadramento, distribuídos ao longo da estrutura social e, no limite, exterminados.

Aos moldes das sociedades disciplinares, Deleuze opõe uma lógica de modulações que nos parece mais elucidativa do que estaria em jogo no contexto da proliferação de dispositivos digitais de reconhecimento facial do que nas referências à eugenia. As várias tecnologias de reconhecimento facial atualmente em uso não 
partem de tipos. Não se trata de aproximar um rosto a algum entre poucos tipos gerados estatisticamente a priori, mas de confrontá-lo a uma quantidade inédita de imagens com um filtro algorítmico que irá revelar, também através do uso de estatística, aquela fotografia arquivada mais semelhante ao rosto-alvo.

Curiosamente, esta lógica também requer de nós uma problematização das articulações entre rosto e representação. Pensemos, por exemplo, nas sociedades que durante a Segunda Guerra Mundial ancoraram parte de suas políticas nos saberes eugênicos. Se as estatísticas de Galton fornecem um tipo judeu a priori, no plano da realidade concreta dos rostos viventes, aquele que mais se aproxime do tipo desenhado pelo estatístico poderia ser considerado um bom representante do grupo. No contexto contemporâneo do reconhecimento facial computadorizado, essa lógica não se sustenta, pois já não estamos falando nos termos de tipos ou grupos, mas de dados - estamos falando de um QR code. Esta diferença técnica permite-nos pensar algumas questões, que desenvolveremos a partir de dois exemplos: o projeto Delegações, do artista turco Ali Miharbi, e o site pornográfico Megacams.

Entre 2007 e 2008, Ali Miharbi desenvolveu e apresentou na Turquia, no México e na Coréia do Sul uma série de trabalhos intitulada Delegações. Com pequenas variações entre as versões exibidas em cada país, o dispositivo funcionava basicamente a partir da visualização, em um monitor LCD, pelo visitante da exposição, de uma imagem de seu rosto, capturada por uma webcam e processada em tempo real. As imagens exibidas eram geradas a partir de uma combinação estatística de características faciais de cada um dos membros dos parlamentos dos respectivos países. De acordo com o próprio artista, a técnica usada para a geração em tempo real das imagens é conhecida como método eigenface, que é utilizado principalmente "para encontrar computacionalmente indivíduos listados ou procurados" (MIHARBI, 2008). No texto de apresentação do projeto, a política de biometria e armazenamento de fotografias tiradas segundo protocolos estritos de alguns países europeus, dos Estados Unidos e do Canadá comparece como referência para o desenvolvimento do dispositivo.

Diante da câmera, algoritmicamente programada para reconhecimento facial, o rosto do visitante é registrado e comparado com outros rostos previamente armazenados no banco de dados. Para desenvolver o projeto o artista criou um banco de dados com fotografias dos políticos que retirou do site dos parlamentos dos respectivos países. A imagem do espectador diante da câmera não é reconstituída em tempo real, mas consiste na imagem "ilegível" que resulta da varredura no banco de dados em busca de seu rosto. Ou seja, caso um dos membros do parlamento de um 
dos referidos países posicione-se diante da câmera, a imagem exibida corresponderá a sua própria fotografia, como se ele estivesse diante de um espelho. Portanto, o uso do método eigenface não culmina, aqui, em uma identificação de qual político seria mais parecido com o espectador, seja racialmente ou a partir de traços singulares de olhos, boca ou nariz. A imagem exibida parece justamente apontar para uma impossibilidade figurativa e representacional que seria inerente a uma sociedade e a um regime escópico estruturados em torno de divíduos.

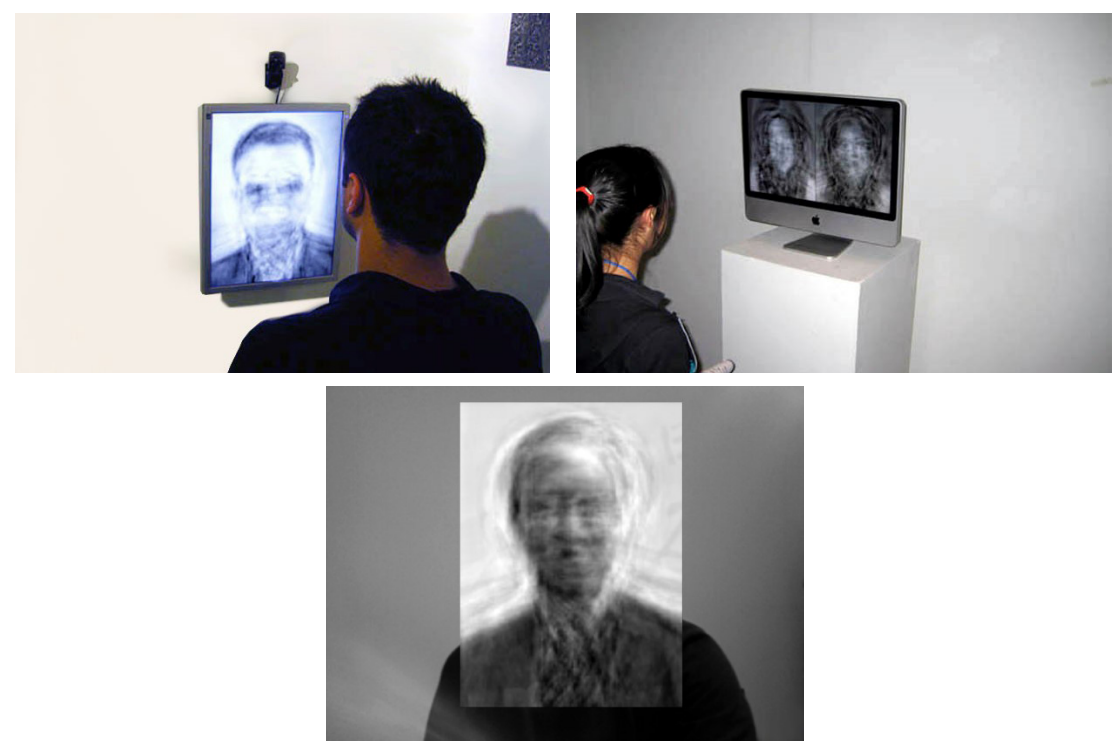

Figuras 4, 5 e 6: Delegação I (Istambul), II (Toluca) e III (Seul), de Ali Miharbi. Respectivamente, a partir do alto à esquerda, em sentido horário.

O projeto de Miharbi equaciona rosto e política, adotando um dispositivo inteligente de produção de imagens como elemento articulador dessas duas esferas. O dispositivo de reconhecimento facial baseado em eigenface funciona nos trabalhos de Miharbi como uma metáfora da crise da representação democrática. O título, Delegações, parece indicar, nesse horizonte, uma ênfase na ação política em detrimento da representação. As únicas representações fiéis possíveis nestas imagens não-especulares do artista turco seriam aquelas geradas a partir de presença dos próprios membros dos respectivos parlamentos diante do dispositivo. O que, segundo nossa leitura, constitui uma crítica arguta à atual incapacidade de se ocupar uma posição em nome do comum.

Uma experiência que lança mão de um método de reconhecimento facial semelhante ao utilizado por Ali Miharbi é o sistema de buscas a partir de imagens de 
rosto que encontramos no site de sexo ao vivo Megacams. O sistema é apresentado, no site, nos seguintes termos:

Você pode carregar uma fotografia de alguém que você queira ver nu(a). Megacams vai escanear sua imagem e confrontar ela com todo(a)s o(a)s modelos de sexo ao vivo em nosso banco de dados. Desta maneira parecerá que você está tendo sexo ao vivo com a pessoa em sua fotografia. Em Megacams fazemos tudo, então você pode curtir sexo ao vivo com modelos dos seus sonhos ${ }^{6}$.

Em Megacams podemos observar uma lógica ligeiramente diferente tanto daquela proposta por Galton quanto daquela que encontramos em operação nos dispositivos criados por Ali Miharbi. Em relação a Galton, a diferença é que em Megacams também é o rosto escolhido pelo usuário que servirá de parâmetro para as buscas e hierarquização das imagens disponíveis no banco de dados da plataforma. Ao receber os links para acesso aos doppelgängers da imagem enviada para a plataforma, acessamos uma lista de perfis organizados em ordem decrescente segundo o percentual de semelhança. Não há aqui, como havia na proposta eugênica de Galton, tipos a priori. Quanto à diferença em relação aos princípios que organizam os dispositivos de Miharbi, Megacams, por atuar em uma esfera vinculada ao desejo e ao imaginário acaba permanecendo atrelado ao princípio da representação, cuja impossibilidade, no plano da política, é salientada pelo projeto do artista turco.

A mesma ferramenta de reconhecimento facial computadorizado e baseado em estatística parece apontar para dois caminhos diversos: por um lado, parece inscrever no plano dos rostos a crise política e epistemológica da representação sublinhando, ao mesmo tempo, a estratégia alternativa de captura individualizante baseada no tratamento biométrico do rosto como um QR code; por outro lado, o privilégio conferido ao rosto nas dinâmicas sociais de identificação, empatia e desejo alimentam a fantasia que está na base de Megacams. Mas não podemos perder de vista toda uma economia do olhar e do rosto que singulariza a relação com a imagem pornográfica, como bem observou Giorgio Agamben (2016, p. 76):

Nas fotografias pornográficas, acontece com frequência que os sujeitos retratados olhem, com um estratagema calculado, em direção à objetiva, exibindo, assim, a consciência de estar exposto ao olhar. Esse gesto imprevisto desmente violentamente a ficção implícita no consumo de tais imagens, segundo a

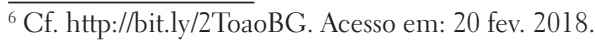


qual aquele que as olha surpreende, não visto, os atores: estes afrontam conscientemente o olhar, obrigam o voyeur a olhá-los nos olhos. Naquele átimo, a natureza insubstancial do rosto humano emerge repentinamente à luz. Que os atores olhem para a objetiva, significa que eles mostram estar simulando; e, todavia, paradoxalmente, propriamente na medida em que exibem a falsificação, eles parecem mais verdadeiros.

Megacams radicaliza a proposição de Agamben na medida em que permite o acesso a vídeos transmitidos ao vivo nos quais o olhar dos atores direto para a câmera e, portanto, para o espectador não constitui um lapso, mas a própria natureza da mise-en-scène desse tipo de produção. Ao mesmo tempo, a lógica que culmina na veracidade vislumbrada por Agamben nas imagens fotográficas, a partir da revelação de sua falsidade, parece tornar-se obsoleta nos vídeos de Megacams na medida que tais vídeos apresentam um exibicionismo conscientemente encenado para um olhar que se encontra do outro lado da tela e que pode, eventualmente, interagir textualmente, solicitando do ator ou da atriz a realização de determinada ação. A questão que fica em aberto seria em que medida a semelhança obtida através de tecnologias de reconhecimento facial do rosto do ator ou da atriz pornô com um rosto familiar ao usuário poderia efetivamente tornar mais crível (e excitante) esta representação. O que há no rosto que permite aos desenvolvedores de Megacams supor que esta parte do corpo pode ancorar e concentrar o desejo sexual?

Não temos resposta para estas questões, mas acreditamos que elas podem ser iluminadas por algumas ideias formuladas por Gilles Deleuze e Félix Guattari (1980). Em uma breve passagem de Mil platôs, os filósofos traçam algumas relações entre o corpo e o rosto, que podem nos ajudar a compreender porque, mesmo em um site de conteúdo pornográfico, no qual nenhuma parte do corpo estaria, em tese, interditada ao olhar do espectador, é a busca através de reconhecimento facial que se apresenta como uma ferramenta capaz de conferir maior autenticidade ao consumo de pornografia. Eles escrevem:

Disciplinaremos os corpos, desfaremos a corporeidade, faremos a caça aos devires-animais, empurraremos a desterritorialização até um novo limite, então saltaremos dos estratos orgânicos aos estratos de significância e de subjetivação. Produziremos uma só substância de expressão. Construiremos o sistema parede brancaburaco negro, ou em vez disso, dispararemos esta máquina abstrata que deve justamente permitir e garantir a onipotência do significante, como a autonomia do sujeito. Vocês serão presos [épinglés] sobre a parede branca, enfiados no buraco negro. Esta máquina é dita de rostidade porque ela é produção social do 
rosto, porque ela opera uma rostificação de todo o corpo, dos seus entornos e dos seus objetos, uma paisagificação de todos os mundos e meios. A desterritorialização do corpo implica uma reterritorialização sobre o rosto; a descodificação do corpo implica uma sobrecodificação pelo rosto; o colapso das coordenadas corporais ou dos meios implica uma constituição de paisagem. A semiótica do significante e do subjetivo não passa nunca pelo corpo. É uma absurdidade fingir colocar o significante em relação com o corpo. Ou pelo menos não é senão com um corpo já inteiramente rostificado. (DELEUZE; GUATTARI, 1980, p. 222)

Nos inscrevemos na esteira do pensamento da dupla de autores franceses para lançar luz sobre a centralidade do rosto no sistema de buscas em operação em Megacams. Não se trata aqui de moralizar o consumo e a produção de material pornográfico que, como sabemos, integra um campo suficientemente vasto e heterogêneo para exceder o escopo deste artigo. A questão que nos interessa é a da construção do rosto e do que a proliferação das máquinas abstratas de rostidade sintomatizariam com respeito ao terreno político, social, econômico e estético no qual nos encontramos. No trecho acima citado, os filósofos opõem o regime das corporeidades, dos mundos e dos meios ao regime que produz rostos e paisagens. Estes últimos resultam do encontro entre dois eixos: de significância e de subjetivação. A construção social de rostos e paisagens parece, portanto, vincular-se a duas necessidades fundamentais, que se atrelam à necessidade de controle que pauta nossas sociedades: o sentido e o sujeito. Ficam de fora desta lógica, a vibratilidade e organicidade do corpóreo.

\section{Referências}

AGAMBEN, G. Homo sacer: o poder soberano e a vida nua I. Belo Horizonte: Editora UFMG, 2002.

Mezzi senza fine: note sulla politica. Torino: Bollati Boringhieri, 2016.

APPLE buys artificial intelligence startup Emotient: WSJ. Reuters: technology news. 7 jan. 2016. Disponível em: <https://reut.rs/1Phz3OX>. Acesso em: 25 fev. 2018.

BRUNO, F. "Contramanual para câmeras inteligentes: vigilância, tecnologia e percepção”. Galáxia, São Paulo, n. 24, p. 47-63, 2012.

DELEUZE, G. Conversações. São Paulo: Editora 34, 2006.

DELEUZE, G.; GUATTARI, F. Mille plateaux: capitalisme et schizophrénie 2. Paris: Minuit, 1980. 
EDKINS, J. Face politics. London: Routledge, 2015.

ERNST, W; FAROCKI, H. "Towards an archive for visual concepts". In. ELSAESSER, T. (Org.) Harun Farocki: working on the sight-lines. Amsterdam: Amsterdam University Press, 2004.

FOUCAULT, M. História da sexualidade I: a vontade de saber. Rio de Janeiro: Graal, 1988.

GATES, K. A. Our biometric future: facial recognition technology and the culture of surveillance. Nova York: NYU Press, 2011.

GUNNING, T. "Tracing the individual body: photography, detectives, and early cinema". In. CHARNEY, L; SCHWARTZ, V. R. (Orgs.) Cinema and the invention of modern life. Berkeley: University of California Press, 1995.

JOHNSON, S. Cultura da interface. Rio de Janeiro: Zahar, 2001.

MASCARO, G. "Não é sobre sapatos". Texto de apresentação de projeto artístico. 2014. Disponível em: <https://bit.ly/2QK3clF>. Acesso em: 25 fev. 2018.

MIHARBI, A. "Delegations". Texto de apresentação de projeto artístico. 2008. Disponível em: <https://bit.ly/2RQCDJ3>. Acesso em: 25 fev. 2018.

MONTAGNER, C. "Dados biométricos dos paulistanos são coletados no metrô sem consentimento nem debate das implicações". Lavits: rede latino-americana de estudos sobre vigilância, tecnologia e sociedade. 2 mai. 2018. Disponível em: <https:// bit.ly/2L7X29M>., Acesso em: 18 jun. 2018.

REVEL, J. "Nas origens do biopolítico: de 'Vigiar e punir' ao pensamento da atualidade" In: KOHAN, W. O.; GONDRA, J. Foucault 80 anos. Belo Horizonte: Autêntica, 2006.

SEKULA, A. "The body and the archive". October, Cambridge, v. 39, p. 3-64, winter1986.

SINNREICH, A. "How facial recognition is turning people into human bar codes". MarketWatch: Opinion. 13 de abril de 2017. Disponível em: <https://on.mktw. net/2n6H2aL $>$. Acesso em: 25 fev. 2018.

submetido em: 18 jun. 2018 | aprovado em: 26 out. 2018 